\title{
Effect of angiotensin receptor blockade on endothelial function: focus on olmesartan medoxomil
}

\author{
Carlos Ferrario \\ Hypertension and Vascular Disease \\ Center, Wake Forest University \\ School of Medicine, Winston-Salem, \\ NC, USA
}

\begin{abstract}
Endothelial dysfunction is the common link between cardiovascular disease risk factors and the earliest event in the cascade of incidents that results in target organ damage. Angiotensin II, the terminal pressor effector arm of the renin-angiotensin-aldosterone system, increases blood pressure (BP) by vasoconstriction and sodium and fluid retention, and has a pro-oxidative action that induces endothelial dysfunction and contributes to vascular remodeling. Angiotensin receptor blockers (ARBs) reduce BP and morbidity and mortality in patients with hypertension, ventricular hypertrophy, diabetes mellitus, and renal disease. Olmesartan medoxomil is a long-acting, well-tolerated, effective ARB that prevents or reverses endothelial dysfunction in animal models of atherosclerosis, hypertension, diabetes, nephropathy, and retinopathy. Olmesartan medoxomil, a prodrug of olmesartan approved for the treatment of hypertension, has been shown to ameliorate endothelial dysfunction in patients with hypertension or diabetes. In randomized studies, the drug reduces vascular inflammation and the volume of large atherosclerotic plaques, increases the number of regenerative endothelial progenitor cells in the peripheral circulation, improves endothelium-dependent relaxation, and restores the normal resistance vessel morphology. Importantly, the impact of olmesartan medoxomil on endothelial dysfunction is thought to be independent of BP lowering.
\end{abstract}

Keywords: endothelial dysfunction, angiotensin receptor blocker, olmesartan medoxomil, hypertension, atherosclerosis

\section{Introduction}

Major advances in the treatment of cardiovascular disease (CVD) have been accompanied by the development of effective prevention strategies. ${ }^{1,2}$ In spite of these advances, CVD continues to be the leading cause of death in most countries in the world. ${ }^{3}$ The ongoing epidemic of obesity and increasing prevalence of diabetes mellitus and chronic kidney disease will further contribute to keeping diseases of the heart and blood vessels as the predominant cause of cardiovascular mortality. ${ }^{4-6}$

The common link between CVD risk factors such as hypertension, diabetes, and smoking is now recognized to be vascular endothelial dysfunction. ${ }^{7}$ Under normal circumstances, the vascular endothelium influences vessel tone and modulates structure, vessel permeability, adhesion and migration of inflammatory cells, and hemostasis. In addition, the healthy vascular endothelium has a role in the prevention of oxidative damage. In contrast, endothelial dysfunction may be one of the earliest events initiating the cascade of maladaptive changes that contribute to target organ damage. ${ }^{8}$

Endothelial dysfunction of the coronary arteries is associated with an increased CVD risk. ${ }^{9}$ In addition to the conventional cardiovascular risk factors (coronary artery disease [CAD], age, and body mass index), markers of endothelial dysfunction were identified as independent predictors of adverse events during a mean of 46 months 
of follow-up in a prospective study in patients undergoing cardiac catheterization. ${ }^{9}$ Markers of endothelial dysfunction that predicted adverse outcomes included the change in coronary vascular resistance $(\triangle \mathrm{CVR})$ after intracoronary administration of acetylcholine and epicardial constriction with acetylcholine. Survival was improved in patients with the best microvascular responses after a 2-minute intracoronary infusion of acetylcholine. ${ }^{9}$

Carotid artery intima-media thickness (IMT) is linearly correlated with the risk of myocardial infarction (MI) and stroke. ${ }^{10}$ A recent meta-analysis of eight studies showed that the risk of $\mathrm{MI}$ increased by approximately $25 \%$ and the risk of stroke increased by approximately $15 \%$ for each increase of one standard deviation in carotid artery IMT. ${ }^{10}$ Other studies have demonstrated reduced endothelial vasodilator capacity in siblings of hypertensive subjects. ${ }^{11,12}$ The common factor responsible for this phenomenon may be a novel polymorphism in the principal arginine transporter that accounts, at least in part, for the link between endothelial dysfunction, L-arginine, nitric oxide metabolism, and essential hypertension. ${ }^{13}$

\section{Natural history of endothelial dysfunction}

The development and progression of atherosclerosis is a result of inflammatory processes including expression of markers of endothelial activation. ${ }^{14}$ For example, vascular cell adhesion molecule-1 facilitates the binding of monocytes and T-lymphocytes to vessel walls. A variety of cytokines and growth factors, such as macrophage colony-stimulating factor-1 (M-CSF-1) and transforming growth factor (TGF)- $\alpha$ and TGF- $\beta$, are released from inflammatory lesions, recruit additional leucocytes, and stimulate proliferation of vascular smooth muscle cells.

As discussed elsewhere, the presence of monocytes in the intima is a characteristic of the early stages of plaque formation. ${ }^{15-18}$ Chemoattractant substances such as monocyte chemoattractant protein-1 (MCP-1) are generated by vascular inflammation and promote infiltration of monocytes into the intima. After infiltrating the vascular endothelium, monocytes are transformed into tissue macrophages, which engulf lipid particles and become "foam cells". Accumulation of foam cells gives rise to a visible fatty streak on the luminal surface of arteries. Work by the author and his associates first established an obligatory role of angiotensin II (Ang II) in mediating the cascade of initiating events leading to the appearance of foam cells. ${ }^{15-18}$
Endothelial dysfunction involves accumulation of lipids, inflammation, and proliferation of vascular smooth muscle cells. Recruitment of inflammatory cells, proliferation of vascular smooth muscle, and accumulation of lipids by foam cells all contribute to thickening of the intima and the creation of an atherosclerotic plaque. Atherosclerosis occurs preferentially in areas of turbulent blood flow and low shear stress. ${ }^{19}$

\section{Role of the renin-angiotensin- aldosterone system (RAAS) in endothelial dysfunction}

The renin-angiotensin-aldosterone system (RAAS) has a well-established role in the regulation of sodium levels, fluid balance, and blood pressure (BP). Emerging evidence suggests that this system is also involved in the pathophysiology of type 2 diabetes mellitus and obesity. ${ }^{20-26}$

The classical view of the RAAS holds that the octapeptide Ang II is the terminal effector in this endocrine signaling pathway, and that upon binding to Ang II type 1 ( $\mathrm{AT}_{1}$ ) receptors, vasoconstriction and sodium and water retention occur, along with mitogenic and proliferative effects on vascular endothelial and smooth muscle cells. ${ }^{27}$ There is evidence that Ang II is involved in pathologic inflammation, and that it increases oxidative stress by regulating nicotinamide adenine dinucleotide phosphate (NADPH) levels, the principal source of reactive oxygen species (ROS) in the vasculature. Ang II also accelerates senescence of endothelial progenitor cells (EPCs). ${ }^{28}$ Senescence of EPCs is accelerated in patients with essential hypertension, and patients with $\mathrm{CAD}$ have fewer EPCs in peripheral blood. ${ }^{29}$

A seminal study assessing the role of Ang II in the development of atherosclerosis in primates first documented a critical contribution of the renin-angiotensin system in the origin of fatty streak formation. In this study, ${ }^{30}$ the administration of the angiotensin receptor blocker (ARB), losartan, prevented the development of aortic fatty streak formation by a mechanism independent of BP. The central role of Ang II in endothelial dysfunction and atherosclerotic plaque formation is illustrated in Figure 1. Later studies in knockout mice confirm that the $\mathrm{AT}_{1}$ receptor is involved in atherosclerosis. Apolipoprotein E knockout mice (ApoE-/-) have impaired endotheliumdependent vasodilation, significantly higher superoxide radical release rates, and develop marked atherosclerotic lesions when fed a high cholesterol diet. In contrast, $\mathrm{AT}_{1}-/$ - mice have greatly reduced vascular oxidative stress, endothelial dysfunction, and atherosclerotic lesion formation irrespective of BP and plasma cholesterol levels. When ApoE-/- mice were crossbred 


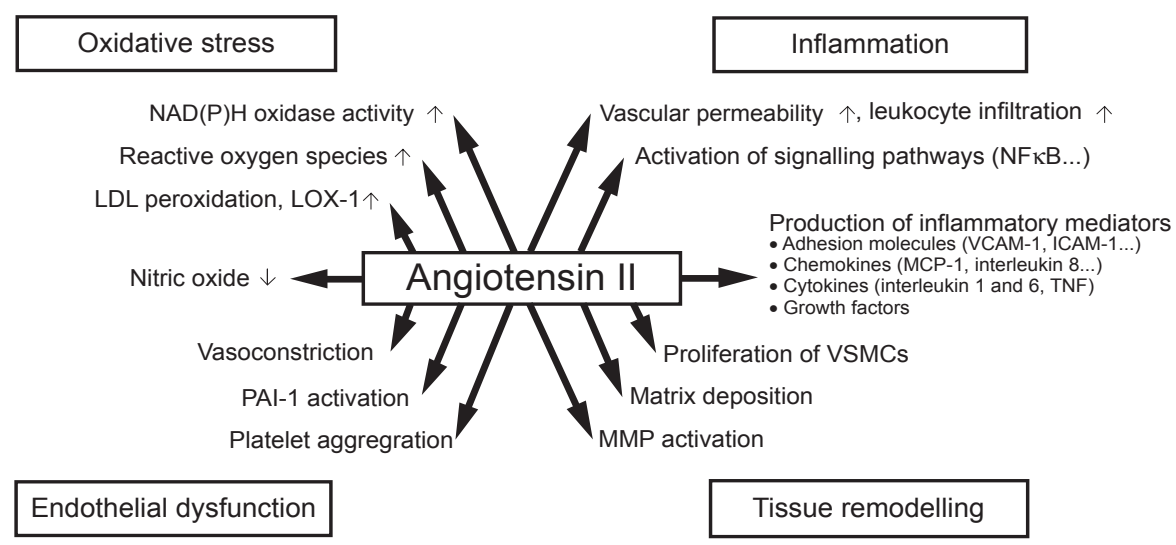

Figure I Atherosclerotic plaque formation in relationship to Ang II. Reprinted from the Lancet, 369, Schmeider RE, Hilgers KF, Schlaich MP. Renin-angiotensin system and cardiovascular risk, 1208-1219.109 Copyright @ 2007, with permission from Elsevier.

Abbreviations: ICAM-I, intercellular adhesion molecule-I; LDL, low-density lipoprotein; LOX-I, lectin-like oxidized low-density lipoprotein receptor-I; MCP-I, monocyte chemoattractant protein-I; MMP, matrix metalloproteinase; NADPH, nicotinamide adenine dinucleotide phosphate; NRB, norbormide; PAI-I, plasminogen activator inhibitor-I; TNF, tumor necrosis factor; VCAM-I, vascular cell adhesion molecule-I;VSMCs, vascular smooth muscle cells.

with $\mathrm{AT}_{1}-/$ - mice, the resulting progeny (ApoE-/-, $\left.\mathrm{AT}_{1}-/-\right)$ had significantly lower BP levels and superoxide release rates than ApoE-/- mice and did not develop atherosclerosis. These studies suggest a fundamental role of $\mathrm{AT}_{1}$ receptor activation in atherogenesis. ${ }^{31}$ In the pursuit of the mechanism accounting for the actions of Ang II in atherogenesis, we found that early activation of monocytes occurred through upregulation of the bone marrow renin-angiotensin system, whereby hypercholesterolemia stimulates the expression of bone marrow CD1 $1 b^{(+)}$ receptors in monocytes. ${ }^{32-34}$

Over the last decade, it has become clear that the classical view of the RAAS is in need of revision. An additional RAAS effector that counterbalances the biological actions of Ang II has been isolated and characterized. This additional effector, the heptapeptide Ang-(1-7), is a fragment produced by hydrolysis of Ang I by several tissue-specific endopeptidases (prolyl oligopeptidase and thimet oligopeptidase in vascular endothelial and smooth muscle cells, and neprilysin in kidney cells) that bind to the G-protein-coupled mas receptor. ${ }^{35-38}$ More recently, it has been shown that Ang-(1-7) is also produced by a homolog of angiotensin-converting enzyme (ACE), known as angiotensin-converting enzyme 2 (ACE2). ACE2 is a membrane-bound metallopeptidase that has a high specificity for Ang II and acts to regulate the balance between Ang II and Ang-(1-7) in tissues via a mitogen-activated protein kinase phosphatase. ${ }^{27,39}$ Like Ang II, Ang-(1-7) is pleiotropic; however, in contrast to the effects of Ang II, Ang-(1-7) acts as a vasodilator and growth inhibitor and has been shown to counter-regulate the effects of Ang II in human endothelial cells. ${ }^{40}$ The role of Ang-(1-7) in CVD and hypertension is shown in Table 1.
Disruption of ACE2 resulted in marked increases in Ang II levels and cardiac contractility defects in rat models of hypertension. ${ }^{41}$ In contrast, ablation of ACE in ACE2deficient mice restored the normal cardiac phenotype. ${ }^{41}$ These data demonstrate that a counter-regulatory balance exists between the two arms of the RAAS, as illustrated in Figure 2.

As proposed by Ferrario, ${ }^{42}$ under normal physiological conditions, both the ACE/Ang II and the ACE2/Ang(1-7) axes of the RAAS strike a balance between proliferative and antiproliferative effects. However, when a physiological imbalance occurs as a result of a pathological process, such as increased activity of the $\mathrm{ACE} / \mathrm{Ang} \mathrm{II} / \mathrm{AT}_{1}$ receptor axis, the failure of compensation by the opposing axis favors hypertension and consequent cardiovascular remodeling.

Drugs that target and block the effects of Ang II would be expected to prevent or reverse endothelial dysfunction and improve long-term morbidity and mortality outcomes in a broad spectrum of patients. This is, indeed, the case. Three classes of agents, ACE inhibitors, ARBs, and, most recently, direct renin inhibitors (DRIs), have been developed to specifically target the RAAS. Most experience has been gained with ACE inhibitors and ARBs, which are widely approved and used for the treatment of hypertension and prevention of CVD, although a recent study showed that aliskiren resulted in striking reductions of atherosclerosis in fat-fed low-density lipoprotein (LDL) receptor-deficient (LDLr-/-) mice. ${ }^{43}$

ARBs selectively target the $\mathrm{AT}_{1}$ receptor and have a wellestablished role in the management of hypertension. Drugs in this class have been shown to improve outcomes in patients with hypertension, ventricular hypertrophy, diabetes mellitus, renal disease, and congestive heart failure. ${ }^{44-51}$ 
Table I Ang-(I-7) in cardiovascular disease and hypertension

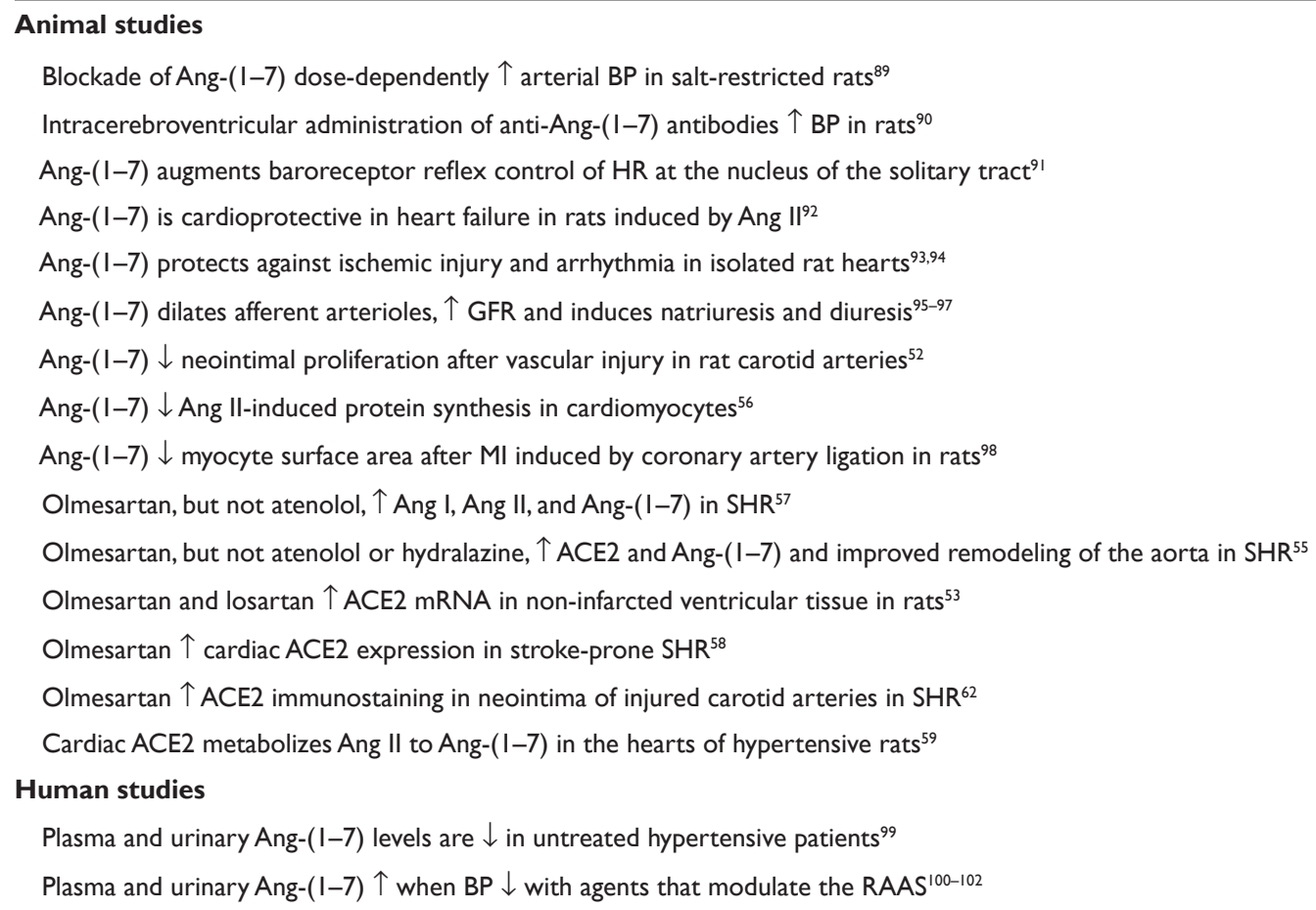

Abbreviations: ACE, angiotensin-converting enzyme; Ang, angiotensin; BP, blood pressure; GFR, glomerular filtration rate; HR, hypertensive rats; MI, myocardial infarction; mRNA, messenger ribonucleic acid; RAAS, renin-angiotensin-aldosterone system; SHR, spontaneously hypertensive rats.

Within the ARB class, olmesartan medoxomil is a long-acting Ang II antagonist approved for the treatment of mild to severe hypertension, alone or in combination with other agents. In addition to producing sustained reductions in BP, the drug corrects the underlying defects that lead to endothelial dysfunction in animal models of CVD, and in patients with CVD or hypertension. Moreover, the beneficial effects of the drug on endothelial dysfunction have been shown to complement those of the 3-hydroxy-3-methyl-glutaryl coenzyme A (HMG-CoA) reductase inhibitors. Intriguing evidence suggests that olmesartan upregulates cardiac and vascular expression of ACE2, which leads to greater conversion of Ang II into the vasodilator and anti-proliferative peptide Ang-(1-7) ${ }^{27,30,39,42,52-62}$ The purpose of this paper is to review the extensive literature on the effects of olmesartan medoxomil on endothelial dysfunction, both in humans and animal models.

\section{Studies in humans}

Olmesartan medoxomil produces broad-based improvements in endothelial dysfunction in patients with hypertension. The drug reduces vascular micro-inflammation, decreases the volume of large atherosclerotic plaques, improves endothelium-dependent relaxation, and restores normal resistance vessel morphology. An overview of beneficial effects of olmesartan medoxomil on endothelial function in humans is provided in Table 2 .

\section{Effect of olmesartan medoxomil on markers of vascular inflammation: the EUTOPIA study}

Olmesartan medoxomil significantly reduced vascular inflammation in patients with hypertension in the European Trial on Olmesartan and Pravastatin in Inflammation and Atherosclerosis (EUTOPIA) study. EUTOPIA was a randomized, placebo-controlled, multicenter study in 199 patients with hypertension and vascular micro-inflammation. Vascular micro-inflammation was defined as the presence of any diagnosed atherosclerotic disease (eg, coronary or peripheral arterial disease), type 2 diabetes mellitus, and/or an LDL-cholesterol level between 3.89 and $6.48 \mathrm{mmol} / \mathrm{L}$ $(152-253 \mathrm{mg} / \mathrm{dL}){ }^{63}$ In addition to hypertension (seated diastolic $\mathrm{BP}$ [SeDBP] of 95 to $110 \mathrm{mmHg}$ ), eligible patients were required to have a high-sensitivity $\mathrm{C}$-reactive protein (hsCRP) concentration $>3 \mathrm{mg} / \mathrm{L}$ but $\leq 20 \mathrm{mg} / \mathrm{L}$, and detectable serum levels of interleukin-6 (IL-6) and intercellular adhesion molecule-1 (ICAM-1) ${ }^{63}$ Patients were randomized to 12 weeks of treatment with olmesartan medoxomil $20 \mathrm{mg} /$ day 


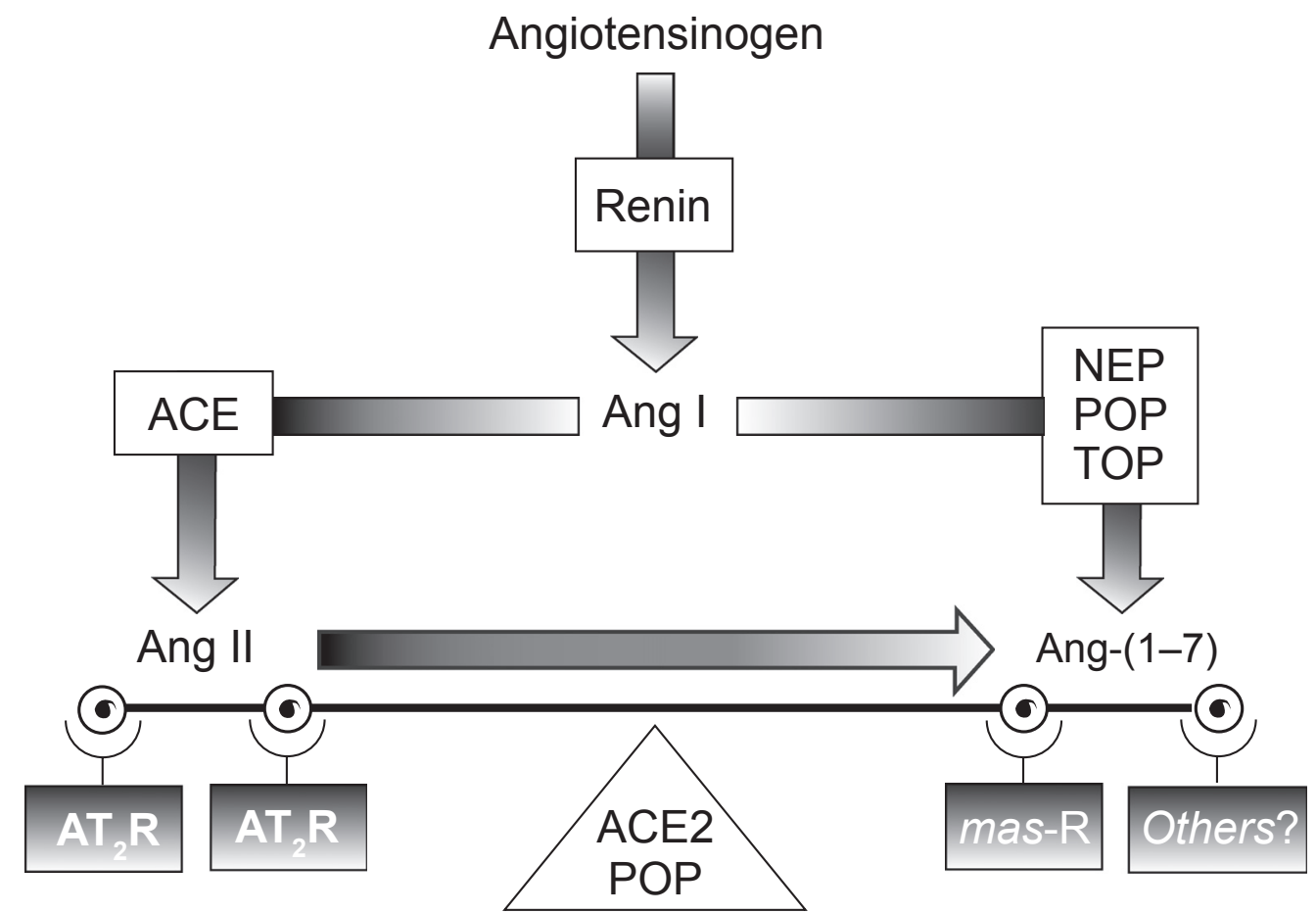

Figure 2 The renin-angiotensin-aldosterone system. Reproduced with permission from Trask AJ, Ferrario CM. Angiotensin-(I-7): pharmacology and new perspectives in cardiovascular treatments. Cardiovasc Drug Rev. 2007;25(2):162-174.60 Copyright @ 2007. Blackwell Publishing.

Abbreviations: ACE, angiotensin-converting enzyme; Ang, angiotensin; $\mathrm{AT}_{1} \mathrm{R}$, angiotensin type I receptor; $\mathrm{AT}_{2} \mathrm{R}$, angiotensin type 2 receptor; NEP, neprilysin; POP, prolyl oligopeptidase; TOP, thimet oligopeptidase.

or placebo. Hydrochlorothiazide 12.5 or $25 \mathrm{mg} /$ day could be added for patients whose SeDBP remained $\geq 90 \mathrm{mmHg}$. After 6 weeks of double-blind treatment, all patients started treatment with the HMG-CoA reductase inhibitor pravastatin $20 \mathrm{mg} /$ day and continued treatment for the remainder of the study. ${ }^{63}$ The final full analysis set comprised 100 patients in the olmesartan medoxomil and 99 patients in the placebo treatment groups.

The primary outcome was the impact of olmesartan medoxomil (alone or in combination with pravastatin) on a panel of anti-inflammatory measures: hsCRP, high sensitivity tumor necrosis factor- $\alpha$ (hsTNF- $\alpha$ ), IL-6, ICAM-1, and MCP-1. ${ }^{63}$ Olmesartan medoxomil produced significant reductions from baseline in hsCRP, hsTNF- $\alpha$, IL-6, and MCP-1 (all comparisons $\mathrm{p}<0.05$ vs baseline), but not ICAM-1, after 6 and 12 weeks of treatment. In contrast, there were no statistically significant reductions from baseline in any inflammatory markers in patients treated with placebo, with the exception of IL-6 at Week 6 (but not at Week 12). ${ }^{63}$ The difference in hsTNF- $\alpha$ between olmesartan medoxomil and placebo recipients at Week 12 was statistically significant.

There were no significant changes in the serum lipid profile between baseline and Week 6 in recipients of olmesartan medoxomil or placebo. As expected, the addition of pravastatin produced significant reductions in total cholesterol and LDL cholesterol between Week 6 and Week 12 of treatment in both groups. ${ }^{63}$ Systolic BP (SBP)/DBP decreased significantly compared with baseline in both treatment groups, with significantly greater reductions achieved with olmesartan medoxomil than placebo at all time points with the exception of SBP at Week $12 .^{63}$

\section{Effect of olmesartan medoxomil on EPCs in patients with type 2 diabetes mellitus}

ARBs increase the number of regenerative EPCs in peripheral blood of patients with type 2 diabetes mellitus, a condition associated with endothelial dysfunction. ${ }^{64}$ In a randomized, double-blind, placebo-controlled study, before treatment with olmesartan medoxomil, the number of EPCs was significantly lower in 18 patients with type 2 diabetes mellitus and hypertension compared with 38 age-matched healthy volunteers. ${ }^{64}$ After 12 weeks of treatment with olmesartan medoxomil $40 \mathrm{mg} /$ day $(\mathrm{n}=9)$, the number of circulating EPCs increased significantly in patients with type 2 diabetes mellitus (from 231 to 465 per high power field width, $\mathrm{p}<0.05$ vs placebo). There was no change in the number of $\mathrm{CD} 34^{+}$hematopoietic progenitor cells after treatment with olmesartan medoxomil. 
Table 2 Overview of beneficial effects of olmesartan medoxomil on endothelial function in humans

\begin{tabular}{l}
\hline Effects of olmesartan medoxomil in humans with hypertension ${ }^{55-59}$ \\
\hline Reduce vascular micro-inflammation \\
$\downarrow$ hsCRP (vs baseline) \\
$\downarrow$ hsTNF- $\alpha$ (vs baseline) \\
$\downarrow$ IL-6 (vs baseline) \\
$\downarrow$ MCP-I (vs baseline) \\
$\uparrow$ number of regenerative EPCs in peripheral blood \\
$\downarrow$ volume of large atherosclerotic plaques (vs atenolol) \\
Improved endothelium-dependent coronary artery dilation \\
$\uparrow$ change in corrected myocardial blood flow \\
$\downarrow$ change in coronary vascular resistance from rest to after a cold pressor test as measured by positron emission tomography \\
Restores normal resistance vessel morphology in patients with hypertension \\
$\downarrow$ mean augmentation index (augmentation pressure/pulse pressure), a surrogate measure of vascular compliance \\
$\downarrow$ wall width, media cross-sectional area, and wall-to-lumen ratio of resistance arteries in gluteal subcutaneous biopsies
\end{tabular}

Abbreviations: EPC, endothelial progenitor cells; hsCRP, high-sensitivity C-reactive protein; hsTNF, high-sensitivity tumor necrosis factor; IL-6, interleukin-6; MCP-I, monocyte chemoattractant protein-I.

\section{Effect of olmesartan medoxomil} on atherosclerotic lesions: the MORE study The results of the Multicentre, Olmesartan, atherosclerosis Regression Evaluation (MORE) study suggest that olmesartan medoxomil reduces the volume of larger atherosclerotic plaques in patients with hypertension, independent of BP reduction. ${ }^{65}$ After 2 years of treatment, there was no statistically significant difference between treatment groups in the IMT of the common carotid artery (CC-IMT), as determined by 2-dimensional ultrasound, the primary efficacy outcome in the trial. Among patients randomized to olmesartan medoxomil $(20-40 \mathrm{mg}$ /day, $\mathrm{n}=78$ ), the mean change in CC-IMT was $-0.090 \mathrm{~mm}$, and among those randomized to atenolol (50-100 $\mathrm{mg} / \mathrm{day}$, $\mathrm{n}=77$ ), the mean reduction in CC-IMT was $-0.082 \mathrm{~mm}$. The overall mean change in plaque volume, as determined by 3 -dimensional ultrasound, was $-4.4 \mu \mathrm{L}$ in patients randomized to olmesartan medoxomil and $+0.1 \mu \mathrm{L}$ in patients randomized to atenolol, although the difference was not statistically significant. However, the reduction in plaque volume was significantly greater in recipients of olmesartan medoxomil $(-11.5 \mu \mathrm{L})(\mathrm{p}=0.023 \mathrm{vs}$ atenolol $)$ than atenolol $(+0.6 \mu \mathrm{L})$ when the analysis was restricted to patients with a baseline plaque volume greater than or equal to the median value $(33.7 \mu \mathrm{L})$. There was no statistically significant difference in mean SBP/DBP at baseline (158/96 vs $157 / 96 \mathrm{mmHg}$, respectively) or in the mean reduction in SBP/DBP after 2 years of treatment
(-25/-15 vs $-22 /-14 \mathrm{mmHg}$, respectively) between patients randomized to olmesartan medoxomil or atenolol. There was a higher proportion of men $(73 \%$ vs $50 \%$ in the olmesartan medoxomil group), more current smokers ( $38 \%$ vs $31 \%$ in the olmesartan medoxomil group), and more patients with a history of CVD (14\% vs $9 \%$ in the olmesartan medoxomil group) among those randomized to atenolol. ${ }^{65}$ It is possible that technical limitations in terms of resolving differences in the volume of small plaques by 3-dimensional ultrasound sonography accounted for the failure of observing differences in plaque regression.

\section{Effect of olmesartan medoxomil on endothelium-dependent vasodilation}

Olmesartan medoxomil improved endothelium-dependent coronary artery dilation in patients with hypertension in a randomized study in 26 patients with untreated hypertension (BP $>140 / 90 \mathrm{mmHg}$ ). After 12 weeks, the mean decrease in SBP was similar in patients randomized to olmesartan medoxomil $(\mathrm{n}=13 ;-28.7 \mathrm{mmHg})$ or amlodipine $(\mathrm{n}=13$; $-26.7 \mathrm{mmHg}$ ). ${ }^{66}$ However, there was a significant increase of the delta change in corrected myocardial blood flow (before vs after treatment $\mathrm{p}<0.001$ ) and a significant decrease in the $\triangle \mathrm{CVR}$ (before vs after treatment $\mathrm{p}<0.01$ ) from rest after a cold pressor test as measured by positron emission tomography among patients treated with olmesartan medoxomil. ${ }^{66}$ In contrast, 12 weeks of treatment with amlodipine had no effect on either parameter. ${ }^{66}$ 
Among patients treated with olmesartan medoxomil, there was also a significant negative correlation between changes in serum superoxide dismutase (SOD) activity and CVR. ${ }^{58}$

The study by Naya et $\mathrm{al}^{66}$ provides evidence that treatment with an ARB (olmesartan medoxomil) but not a calcium channel blocker (amlodipine) has a salutary effect on the coronary microcirculation and improves endothelium-dependent coronary dilation independent of BP lowering. ${ }^{66}$

\section{Effect of olmesartan medoxomil on vessel morphology: the VIOS study ${ }^{67,68}$}

The objective of VIOS (Vascular Improvement with Olmesartan medoxomil Study) was to examine the impact of olmesartan medoxomil on vascular remodeling in nondiabetic patients with stage 1 hypertension as evaluated in the office setting. A total of 100 patients were randomized to 12 months of treatment with either olmesartan medoxomil $20 \mathrm{mg} /$ day or atenolol $50 \mathrm{mg} /$ day. The dosage of either agent was doubled to achieve optimal BP control, and hydrochlorothiazide, amlodipine, or hydralazine could be added to ongoing therapy.$^{67}$ As a result of this study design, the mean reduction in BP was not statistically different between treatment groups at Week 12, 28, or 52 of treatment.

The mean augmentation index (augmentation pressure/ pulse pressure), a surrogate measure of vascular compliance, decreased significantly between baseline and the end of treatment in olmesartan medoxomil recipients, but was unchanged among atenolol recipients. Significant decreases in central aortic pressure were also documented, with no differences between the two treatment groups. ${ }^{67}$ On the other hand, prior to initiation of the treatment period, measures of central aortic pressure in the overall group of patients averaged $131 \pm 16 \mathrm{mmHg}$, a value that is within the range established for prehypertension by the Seventh Report of the Joint National Committee on Prevention, Detection, Evaluation, and Treatment of High Blood Pressure (JNC 7) classification.

Before initiation of treatment, the wall width (WW), media cross sectional area (MCSA), and wall-to-lumen (W/L) ratio of resistance arteries in gluteal subcutaneous biopsies were all significantly higher in a subgroup of 55 patients with hypertension than in a parallel group of 11 normotensive volunteers. ${ }^{67}$ At baseline, these dimensions were similar in hypertensive patients randomized to olmesartan medoxomil $(n=27)$ or atenolol $(n=22)$; however, after 12 months of treatment with olmesartan medoxomil, but not with atenolol, there was a significant decrease in all of these arteriolar dimensions ( $\mathrm{p}<0.01$ vs baseline). The mean $\mathrm{W} / \mathrm{L}$ ratio in arteries from patients receiving olmesartan medoxomil therapy was significantly reduced after 1 year of treatment compared with baseline ( $11.1 \% \pm 0.5$ vs $14.9 \% \pm 0.8$, respectively; $p<0.01)$ whereas the mean $\mathrm{W} / \mathrm{L}$ ratio in arteries from atenolol-treated patients was not significantly decreased (15.5\% vs $16.0 \%$, respectively; $\mathrm{p}>0.05)$. The mean $\mathrm{W} / \mathrm{L}$ ratio in olmesartan medoxomil recipients $(11.1 \%)$ was similar to that in normotensive controls $(11.0 \%)$ after 1 year of treatment. The VIOS trial demonstrated that 1 year of treatment with olmesartan medoxomil restored the normal resistance vessel morphology in stage 1 hypertension independent of BP lowering. ${ }^{67}$

\section{Studies in animals}

Olmesartan has been shown to reduce oxidative stress and endothelial inflammation, and to prevent or reverse the formation of atherosclerotic lesions and vascular remodeling processes in a variety of animal models of atherosclerosis. The drug has also been shown to have renoprotective effects in animal models of kidney disease and retinoprotective effects in an animal model of retinopathy.

\section{Diabetes, insulin resistance, and metabolic syndrome animal models}

Mice fed a high fat diet have increased oxidative stress in cardiac, vascular, and hepatic tissue. ${ }^{69}$ Olmesartan $5 \mathrm{mg} / \mathrm{kg}$ /day markedly suppressed cardiac inflammation and fibrosis, ameliorated endothelial dysfunction, and retarded vascular remodeling in an animal model of diabetes. ${ }^{69}$ The drug also prevented hepatic steatosis, halted progression of hepatic fibrosis, and suppressed the disruption in vascular endothelial NO synthase (eNOS) dimer. The beneficial effects of olmesartan were associated with a decrease in apoptosis signal regulating kinase-1 (ASK-1). ROS activate ASK-1, which, in turn, has been shown to be involved in Ang II-induced cardiac hypertrophy and remodeling. ${ }^{70}$ Interestingly, hydralazine lowered BP in the same strain of diabetic mice, but, unlike olmesartan, had no effect on cardiac remodeling, vascular endothelial function, or hepatic fibrosis. ${ }^{69}$ Moreover, olmesartan had no effect on any of these parameters in ASK-1-deficient mice. The results of the study suggest that Ang II plays a central role in cardiovascular remodeling and endothelial dysfunction in the setting of diabetes, and that olmesartan prevents vascular remodeling, in part, by attenuating the generation of ROS. ${ }^{69}$

\section{Models of hypertension}

Treatment with olmesartan $15 \mathrm{mg} / \mathrm{kg} /$ day and enalapril $25 \mathrm{mg} / \mathrm{kg} /$ day from age 8 weeks to age 12 weeks significantly decreased the left ventricular weight:body weight ratio and normalized cardiac collagen content and the media:lumen 
ratio in spontaneously hypertensive rats (SHR). Significant improvements in aortic collagen content were also obtained with a lower dose of olmesartan ( $1 \mathrm{mg} / \mathrm{kg} / \mathrm{day})$ but not enalapril ( $2 \mathrm{mg} / \mathrm{kg} /$ day $).^{71}$

In another study in SHR that served as the rationale for the VIOS study (see above ${ }^{67}$ ), olmesartan $10 \mathrm{mg} / \mathrm{kg} /$ day produced a greater reduction in the arteriolar $\mathrm{W} / \mathrm{L}$ ratio than atenolol after 8 weeks of treatment, despite similar reductions in BP. ${ }^{57}$ Treatment with olmesartan significantly increased lumen diameter and significantly decreased WW and the $\mathrm{W} / \mathrm{L}$ ratio of mesenteric arteries compared with control SHR. The improvement in $\mathrm{W} / \mathrm{L}$ ratio was also significantly greater than that achieved with atenolol. Treatment with atenolol also decreased $\mathrm{WW}$ and the $\mathrm{W} / \mathrm{L}$ ratio but did not significantly alter the lumen diameter. The lumen diameter was significantly greater in olmesartan-treated animals than in control rats when exposed to luminal pressures ranging from $20 \mathrm{mmHg}$ to $100 \mathrm{mmHg}$. Atenolol-treated animals did not differ from control animals in this respect. The heart weight:body weight ratio, a measure of cardiac hypertrophy, was significantly decreased in animals treated with olmesartan, but not with atenolol. The results of this study are consistent with those of the 1-year-long VIOS trial in humans and demonstrate that treatment with olmesartan can restore resistance vessel morphology after pathological changes have occurred.

Olmesartan reduced the production of ROS, suppressed tissue infiltration of macrophages, and prevented ventricular hypertrophy and fibrosis in hypertensive Dahl salt-sensitive rats with advanced heart failure who were administered olmesartan from age 17 weeks to age 20 weeks. ${ }^{72}$ The addition of olmesartan $0.3 \mathrm{mg} / \mathrm{kg} /$ day to ongoing treatment with an ACE inhibitor (temocapril $0.2 \mathrm{mg} / \mathrm{kg} /$ day) produced further reductions in 4-hydroxy-2-nonenal-modified protein levels, a lipid peroxidation product and marker of ROS generation, in addition to those produced by the ACE inhibitor alone. ${ }^{72}$ The beneficial effects of olmesartan in these models may be attributable, in part, to upregulation of ACE2, which results in increased Ang-(1-7) levels. ${ }^{53,61}$ For example, Yokoyama et $\mathrm{al}^{57}$ detected elevated concentrations of Ang I, Ang II, and Ang-(1-7) in SHR treated with olmesartan, but not atenolol. In another study in SHR, treatment with olmesartan at a dose of $10 \mathrm{mg} / \mathrm{kg} /$ day increased ACE2 and Ang-(1-7) production and was associated with improved vascular remodeling of the aorta. ${ }^{55}$ In this study, olmesartan produced a five-fold increase in ACE2 mRNA in the thoracic aorta. In contrast, neither atenolol nor hydralazine had an impact on ACE2 mRNA expression. Olmesartan selectively reduced the media:lumen ratio and media thickness of the thoracic aorta but not the carotid arteries in this model. These data demonstrate that BP-independent vascular remodeling is regulated by $\mathrm{AT}_{1}$ receptors and can be modulated by treatment with an ARB. ${ }^{55}$

In a subsequent experiment, treatment with olmesartan $10 \mathrm{mg} / \mathrm{kg} /$ day for 14 days produced a $61 \%$ reduction in the cross-sectional area of the neointima of balloon-injured carotid arteries in SHR. ${ }^{62}$ The intensity of ACE2 immunostaining in tissue taken from the injured artery was significantly greater in olmesartan-treated animals compared with vehicle-treated controls. There was no change in neointima thickness or immunostaining intensity in the uninjured contralateral carotid artery, which suggests that changes in ACE2 expression are regulated by a factor other than BP. ${ }^{62}$

Coronary artery ligation-induced MI in normotensive rats results in left ventricular dysfunction and left ventricular hypertrophy, and is associated with increased plasma Ang I, Ang II, angiotensin-(1-7), elevated serum aldosterone, and reduced $\mathrm{AT}-_{1 \mathrm{a}}$ receptor mRNA. ${ }^{53}$ Blockade of $\mathrm{AT}-_{1 \mathrm{a}}$ receptors with an ARB (losartan or olmesartan) for 28 days attenuated cardiac hypertrophy, reduced aldosterone levels, and was associated with further increases in Ang levels. Olmesartan improved contractility; losartan did not. Both ARBs produced a three-fold increase in ACE2 mRNA levels and downregulated $\mathrm{AT}_{-1 \mathrm{a}}$ receptor expression in non-infarcted ventricular tissue..$^{53}$ The beneficial effects of ARB treatment in this model were independent of effects of BP and infarct size. The results suggest that upregulation of ACE2 and increased conversion of Ang II to Ang-(1-7) counterbalances the vasopressor effects resulting from the ACE-mediated conversion of Ang I to Ang II.

\section{Animal models of atherosclerosis}

Hypercholesterolemia-induced atherosclerosis in cynomolgus monkeys (Macaca fascicularis) is similar to that in humans. When maintained on a high cholesterol diet, monkeys develop fatty aortic streaks that can be detected by intravascular ultrasonography; increased levels of TGF- $\beta_{1}$, ICAM-1, and M-CSF; and accumulations of macrophages in the intima, as evidenced by increased binding of specific antibodies in aortic cross sections. ${ }^{30,73,74}$ Treatment with olmesartan $10 \mathrm{mg} / \mathrm{kg} /$ day maintained TGF- $\beta_{1}$, ICAM-1, and M-CSF levels similar to those in control monkeys fed a normal diet; significantly reduced the accumulation of macrophages in the intima; significantly reduced the extent of lipid deposition in the aorta; and significantly reduced the atherosclerotic intima area, and intima area:media area ratio of the aorta. 
In a subsequent 12-month study in the same monkey model of atherosclerosis ${ }^{74}$ treatment with olmesartan $3 \mathrm{mg} / \mathrm{kg} /$ day significantly reduced serum levels of MCP-1, an inflammatory marker, compared with cholesterol-fed monkeys; significantly reduced the intima volume:total volume ratio of the thoracic aorta; and produced significant regression in the size of existing atherosclerotic lesions as indicated by the atherosclerotic area:total surface area of the aorta. Importantly, all of the effects attributable to olmesartan in these studies occurred without significant effects on BP or total cholesterol, LDL-cholesterol, or high-density lipoprotein-cholesterol levels. ${ }^{73,74}$

In Watanabe heritable hyperlipidemic rabbits, the combination of olmesartan and pravastatin had complementary inhibitory effects on atherosclerotic lesions. Olmesartan $0.5 \mathrm{mg} / \mathrm{kg} /$ day and pravastatin $25 \mathrm{mg} / \mathrm{kg} /$ day produced significant reductions in BP and blood cholesterol levels that were accompanied by significant reductions in the surface area and thickness of atherosclerotic lesions and in aortic cholesterol content. The anti-atherosclerotic effects of the two drugs in combination were significantly greater than those produced by monotherapy with either agent. ${ }^{75}$ Immunohistochemical staining of cross sections of aortic tissue showed that both drugs inhibited macrophage infiltration, that pravastatin inhibited lipid deposition, and that olmesartan reduced MCP-1 expression and formation of $\mathrm{N}^{\varepsilon}$-(carboxymethyl)lysine protein adducts, a marker of oxidative stress. ${ }^{75}$

The combination of olmesartan and pravastatin produced additive improvements in left ventricular remodeling in rats with MI induced by ligation of the left anterior descending coronary artery. When administered alone, both drugs decreased cardiomyocyte size; however, the magnitude of the improvement was greater when the two drugs were co-administered. Treatment with the two drugs also downregulated left ventricular atrial natriuretic peptide mRNA. The effects on cardiomyocyte hypertrophy were dose-dependent. ${ }^{75}$

The combination of olmesartan and pravastatin also significantly reduced the progression of atherosclerosis in ApoE*3Leiden transgenic mice, which develop a humanlike lipoprotein profile when fed a cholesterol-rich diet. The number and extent of atherogenic lesions and the number of macrophages and $\mathrm{T}$ lymphocytes per cross section was significantly reduced in mice treated with the combination compared with controls. When administered alone or in combination with pravastatin, olmesartan reduced the quantity of macrophages in lesions compared with control. ${ }^{76}$
The combination of olmesartan and pravastatin improved endothelial function in salt-loaded Dahl salt-sensitive hypertensive rats. ${ }^{77}$ Vascular endothelium-dependent relaxation to acetylcholine, coronary arterial remodeling, and eNOS activity were all significantly improved after 4 weeks of treatment with olmesartan $0.5 \mathrm{mg} / \mathrm{kg} /$ day plus pravastatin $100 \mathrm{mg} / \mathrm{kg} /$ day. Olmesartan prevented disruption of vascular eNOS dimers and downregulation of dihydrofolate reductase to a greater extent than pravastatin; conversely, Akt phosphorylation was enhanced by pravastatin, but not by olmesartan medoxomil.

\section{Studies in ApoE knockout mice}

ApoE knockout mice are predisposed to develop atherosclerosis. When fed a high cholesterol diet, these mice develop marked atherosclerotic lesions in the proximal aorta and exhibit signs of oxidative stress (increased staining for NADPH oxidase, an enzyme that produces ROS).$^{78}$ At a dose of $3 \mathrm{mg} / \mathrm{kg}$ /day, olmesartan significantly inhibited NADPH oxidase activity, decreased superoxide production, reduced the formation of atherosclerotic lesions, and inhibited lipid deposition. ${ }^{78}$ In another study in which apoE knockout mice were fed either a high cholesterol or normal diet for 25 weeks, treatment with olmesartan $10 \mathrm{mg} / \mathrm{kg} /$ day produced significant reductions in the surface area of aortic lesions and the crosssectional area of aortic valves in both groups of mice. ${ }^{79}$

\section{Renoprotective effects}

Olmesartan has been shown to significantly improve urinary protein and $\beta_{2}$-microglobulin excretion, ameliorate glomerular sclerosis and tubulointerstitial injury, and to significantly reduce staining for TGF- $\beta$, vascular endothelial growth factor, and type IV collagen in glomeruli of diabetic rats. ${ }^{80}$ SHR have enhanced intrarenal angiotensinogen production that contributes to increased Ang II levels and leads to hypertension and renal injury. Olmesartan reduced the urinary excretion rate of total protein, prevented glomerular sclerosis, interstitial expansion, and reduced the numbers of monocytes/macrophages in the interstitium or glomeruli of SHR. The drug also reduced angiotensinogen mRNA and protein levels in the kidney cortex, as measured by real-time PCR. ${ }^{81}$ In corpulent SHR, treatment with the drug significantly reduced BP and kidney pentosidine content (which is correlated with proteinuria) and reduced histologic renal damage and proteinuria. ${ }^{82}$ In another study in SHR, olmesartan, but not nifedipine or atenolol, significantly reduced proteinuria and prevented glomerular and tubulointerstitial damage (mesangial activation, podocyte 
injury, tubulointerstitial injury, and inflammatory cell infiltration). The drug also selectively prevented abnormal iron deposition in the interstitium, corrected chronic hypoxia, reduced expression of heme oxygenase and p47 $7^{\text {phox }}$ (a subunit of NADPH oxidase), and inhibited pentosidine formation in this animal model. The unique renoprotective properties of olmesartan were independent of BP reductions and appeared to be attributable to decreased oxidative stress, correction of chronic hypoxia, and inhibition of advanced glycation end product formation, and of abnormal iron deposition. ${ }^{83}$

\section{Retinoprotective effects}

Olmesartan has been shown to have beneficial effects in several animal models of early and late stage retinopathy. The drug prevented elongation of oscillatory potential peaks in a dose-dependent manner in diabetic stroke-prone SHR. In mice with oxygen-induced retinopathy, the drug significantly prevented retinal neovascularization at a dosage of $1 \mathrm{mg} / \mathrm{kg} /$ day. Plasma concentrations of olmesartan in these experiments were comparable to the in vitro $\mathrm{IC}_{50}$ value of the $\mathrm{AT}_{1}$ receptor. ${ }^{84}$

\section{Miscellaneous effects of olmesartan}

Olmesartan has been shown to have antiproliferative effects in animal models of CVD. Olmesartan significantly reduced endothelial inflammatory events in a mouse model of vascular injury that involves the placement of a polyethylene cuff around the femoral artery. ${ }^{85}$ At a dose of $3 \mathrm{mg} / \mathrm{kg} /$ day, the drug significantly reduced TNF- $\alpha$ and MCP-1 levels, which were accompanied by decreased neointima formation and vascular smooth muscle proliferation. In another study that used the same model of endothelial inflammation, olmesartan reduced the number of bromodeoxyuridine-positive vascular smooth muscle cells present in the media and neointima, and prevented phosphorylation of extracellular signal-regulated kinase (ERK, an enzyme associated with progression of fibrosis and cell proliferation) and signal transducer and activator of transcription, all of which indicate that cell division in inflammatory lesions is attenuated by olmesartan. ${ }^{86}$ Treatment with the drug also significantly reduced the rate of DNA synthesis in vascular smooth muscle cells in vitro, as indicated by incorporation of $[3 \mathrm{H}]$-thymidine, and blocked activation of ERK. ${ }^{87}$

Endothelium-dependent relaxation of the aorta of 12-monthold Wistar-Kyoto rats is markedly impaired compared with those of 3-month-old rats. ${ }^{88}$ Thus, aged rats serve as a model for age-related endothelial dysfunction. Tiron, a superoxide scavenger, partially improved endothelium-dependent relaxation in this model, suggesting involvement of superoxide. Treatment of aged rats with olmesartan $5 \mathrm{mg} / \mathrm{kg} / \mathrm{day}$ for 2 weeks significantly reduced superoxide production. Endothelium-dependent relaxation also improved in aged rats after long-term treatment with olmesartan or temocapril, but not cerivastatin or hydralazine. Indomethacin also improved endothelium-dependent relaxation when administered alone, but not after treatment with olmesartan or temocapril. Cyclooxygenase (COX)-2 protein expression and superoxide production were increased in the aortas of aged rats, but were attenuated by olmesartan and temocapril. These results suggest that inhibition of the RAAS corrects age-related endothelial dysfunction, in part, by inhibiting synthesis of COX-2-derived vasoconstricting factors and superoxide anions. ${ }^{88}$

\section{Summary and conclusions}

Endothelial dysfunction is the common link between CVD risk factors and is one of the earliest events in the cascade of changes that results in target organ damage in patients with hypertension. It has been shown that coronary artery endothelial dysfunction is associated with increased CVD risk, and increased carotid artery IMT is predictive of MI and stroke. The large arteries in hypertensive patients are thicker and stiffer than those in normotensive individuals; thus, reversal of the underlying processes that cause these structural changes and normalization of vessel wall dimensions should be a goal of antihypertensive therapy.

Ang II is a potent vasoconstrictor, which promotes sodium and fluid retention and has mitogenic and proliferative effects on vascular endothelial and smooth muscle cells. Under normal physiological conditions, these effects are counterbalanced by Ang-(1-7). In contrast, under pathological conditions, the effects of Ang II become predominant and endothelial dysfunction results. ARBs correct the pathological imbalance in the RAAS, in part, by augmenting the activity of the ACE2/Ang-(1-7) axis. ${ }^{42,54}$

While it would be expected that all Ang II receptor blockers share similar characteristics in terms of the mechanisms of action, both past ${ }^{89}$ and emerging data suggest that this may not be the case. A systematic review, performed to identify the factors that determine the antihypertensive activity of the ARBs using 24-hour ambulatory BP monitoring data from 35 studies, showed the greatest reductions in both SBP and DBP being seen with olmesartan medoxomil. ${ }^{90}$ Studies of the pharmacological characteristics of olmesartan provide support for the clinical findings. In vitro studies of guinea pig aorta showed that olmesartan inhibited Ang II-induced contraction with a potency $160,3.4$, and 1.2 times greater than 
losartan, EXP-3174, and candesartan, respectively. ${ }^{91,92}$ Since the effects of olmesartan lasted for more than 90 minutes after the drug was removed, these data showed that olmesartan acts as a specific and insurmountable antagonist of Ang II-induced vessel contraction. This means that even in the presence of high quantities of Ang II, the physiological response to this mediator shall remain low, whereas a surmountable antagonism (fast reversible binding, short-lasting inhibition) would lead to a full physiological response, even if in the presence of higher doses of the agonist peptide. Additional comparative studies of the pharmacokinetic characteristics of olmesartan showed that the $\mathrm{IC}_{50}$ values for olmesartan receptor binding is eight times greater than telmisartan and 474 times more potent than losartan..$^{93}$ Another interesting feature of olmesartan is its ability to inhibit ACE. This evidence comes from the observation that treatment with olmesartan in stroke-prone SHR decreases plasma Ang II levels while concomitantly elevating plasma Ang-(1-7) levels through increase in ACE2 activity. ${ }^{58}$ The experimental finding is in keeping with a previous report showing no increases in plasma Ang II levels in patients treated with olmesartan for 2 years. ${ }^{94}$ This novel finding contrasts with the known effects of ARBs in increasing plasma levels of Ang II. ${ }^{95}$ Altogether, the data suggest that the molecular characteristics of olmesartan medoxomil confer this drug with unique properties that translate into a greater specificity and actions.

Studies in a wide range of animal models have demonstrated that treatment with olmesartan significantly reduces inflammation, prevents formation of new lesions, and promotes regression of pre-existing atherosclerotic lesions. Improvements have been demonstrated in animal models of atherosclerosis, hypertension, diabetes mellitus, nephropathy, and retinopathy. Studies in animals have also shown that the combination of olmesartan and pravastatin has complementary pleiotropic effects on the progression of atherosclerosis. Olmesartan reduces inflammation, while pravastatin inhibits progression of pre-existing lesions.

Olmesartan medoxomil produces long-lasting and clinically significant reductions in BP in patients with hypertension. It is now clear that broad-based improvements in endothelial dysfunction are also obtained in patients with hypertension that are independent of the BP-lowering effects of the drug. In the randomized, placebo-controlled EUTOPIA trial, olmesartan medoxomil significantly reduced vascular inflammation in patients with hypertension. The drug did not significantly reduce the CC-IMT compared with atenolol after 2 years of continuous treatment in the large randomized
MORE study. However, olmesartan medoxomil did produce significant reductions in the volume of large atherosclerotic plaques compared with atenolol in patients enrolled in this trial. In the VIOS study, 1 year of treatment with olmesartan medoxomil restored the normal morphology of resistance vessels in patients with hypertension. WW, MCSA, and the $\mathrm{W} / \mathrm{L}$ ratio of arteries decreased significantly in recipients of olmesartan medoxomil, but not atenolol. Moreover, the W/L ratio in olmesartan medoxomil-treated patients was restored to the same dimensions as that in normotensive controls at the end of the study. Clinical studies in patients have also shown that olmesartan medoxomil significantly increased the number of regenerative EPCs in the peripheral circulation and improves endothelium-dependent relaxation. Importantly, the positive benefits of olmesartan medoxomil on improving endothelial dysfunction appear to be independent of BP lowering.

\section{Acknowledgments}

The preparation of this article was supported by Daiichi Sankyo, Inc. I thank Blair Jarvis, MSc, and Alan J Klopp, $\mathrm{PhD}$, for providing editorial assistance in the preparation of this review.

\section{Disclosures}

The author declares no conflicts of interest.

\section{References}

1. Hardoon SL, Whincup PH, Lennon LT, Wannamethee SG, Capewell S, Morris RW. How much of the recent decline in the incidence of myocardial infarction in British men can be explained by changes in cardiovascular risk factors? Evidence from a prospective population-based study. Circulation. 2008;117(5):598-604.

2. Kahn R, Robertson RM, Smith R, Eddy D. The impact of prevention on reducing the burden of cardiovascular disease. Circulation. 2008;118(5):576-585

3. Perkovic V, Huxley R, Wu Y, Prabhakaran D, MacMahon S. The burden of blood pressure-related disease: a neglected priority for global health. Hypertension. 2007;50(6):991-997.

4. Coresh J, Selvin E, Stevens LA, et al. Prevalence of chronic kidney disease in the United States. JAMA. 2007;298(17):2038-2047.

5. Fox CS, Coady S, Sorlie PD, et al. Increasing cardiovascular disease burden due to diabetes mellitus: the Framingham Heart Study. Circulation. 2007;115(12):1544-1550.

6. Kestenbaum B, Rudser KD, de Boer IH, et al. Differences in kidney function and incident hypertension: The Multi-Ethnic Study of Atherosclerosis. Ann Intern Med. 2008;148(7):501-508.

7. Munzel T, Sinning C, Post F, Warnholtz A, Schulz E. Pathophysiology, diagnosis and prognostic implications of endothelial dysfunction. Ann Med. 2008;40(3):180-196.

8. Pahkala K, Heinonen OJ, Lagstrom H, et al. Vascular endothelial function and leisure-time physical activity in adolescents. Circulation. 2008;118(23):2353-2359

9. Halcox JP, Schenke WH, Zalos G, et al. Prognostic value of coronary vascular endothelial dysfunction. Circulation. 2002;106(6) 653-658. 
10. Lorenz MW, Markus HS, Bots ML, Rosvall M, Sitzer M. Prediction of clinical cardiovascular events with carotid intima-media thickness: a systematic review and meta-analysis. Circulation. 2007;115(4):459-467.

11. McAllister AS, Atkinson AB, Johnston GD, Hadden DR, Bell PM, McCance DR. Basal nitric oxide production is impaired in offspring of patients with essential hypertension. Clin Sci (Lond). 1999;97(2): 141-147.

12. Schlaich MP, Parnell MM, Ahlers BA, et al. Impaired L-arginine transport and endothelial function in hypertensive and genetically predisposed normotensive subjects. Circulation. 2004;110(24): 3680-3686.

13. Yang Z, Venardos K, Jones E, Morris BJ, Chin-Dusting J, Kaye DM. Identification of a novel polymorphism in the 3'UTR of the L-arginine transporter gene SLC7A1: contribution to hypertension and endothelial dysfunction. Circulation. 2007;115(10):1269-1274.

14. Zhang $\mathrm{C}$. The role of inflammatory cytokines in endothelial dysfunction. Basic Res Cardiol. 2008;103(5):398-406.

15. Ferrario CM, Richmond RS, Smith R, Levy P, Strawn WB, Kivlighn S. Renin-angiotensin system as a therapeutic target in managing atherosclerosis. Am J Ther. 2004;11(1):44-53.

16. Ferrario CM, Strawn WB. Role of the renin-angiotensin-aldosterone system and proinflammatory mediators in cardiovascular disease. Am J Cardiol. 2006;98(1):121-128.

17. Strawn WB, Dean RH, Ferrario CM. Novel mechanisms linking angiotensin II and early atherogenesis. J Renin Angiotensin Aldosterone Syst. 2000;1(1):11-17.

18. Strawn WB, Ferrario CM. Mechanisms linking angiotensin II and atherogenesis. Curr Opin Lipidol. 2002;13(5):505-512.

19. Humphrey JD. Mechanisms of arterial remodeling in hypertension: coupled roles of wall shear and intramural stress. Hypertension. 2008;52(2):195-200.

20. Abuissa H, Jones PG, Marso SP, O’Keefe JH, Jr. Angiotensinconverting enzyme inhibitors or angiotensin receptor blockers for prevention of type 2 diabetes: a meta-analysis of randomized clinical trials. J Am Coll Cardiol. 2005;46(5):821-826.

21. Schupp M, Clemenz M, Gineste R, et al. Molecular characterization of new selective peroxisome proliferator-activated receptor gamma modulators with angiotensin receptor blocking activity. Diabetes. 2005;54(12):3442-3452.

22. Schupp M, Lee LD, Frost N, et al. Regulation of peroxisome proliferator-activated receptor gamma activity by losartan metabolites. Hypertension. 2006;47(3):586-589.

23. Engeli S, Bohnke J, Gorzelniak K, et al. Weight loss and the reninangiotensin-aldosterone system. Hypertension. 2005;45(3):356-362.

24. Engeli S, Schling P, Gorzelniak K, et al. The adipose-tissue renin-angiotensin-aldosterone system: role in the metabolic syndrome? Int J Biochem Cell Biol. 2003;35(6):807-825.

25. Sharma AM. Is there a rationale for angiotensin blockade in the management of obesity hypertension? Hypertension. 2004;44(1):12-19.

26. Sharma AM, Engeli S. The role of renin-angiotensin system blockade in the management of hypertension associated with the cardiometabolic syndrome. J Cardiometab Syndr. 2006;1(1):29-35.

27. Varagic J, Trask AJ, Jessup JA, Chappell MC, Ferrario CM. New angiotensins. J Mol Med. 2008;86(6):663-671.

28. Imanishi T, Hano T, Nishio I. Angiotensin II accelerates endothelial progenitor cell senescence through induction of oxidative stress. J Hypertens. 2005;23(1):97-104.

29. Vasa M, Fichtlscherer S, Aicher A, et al. Number and migratory activity of circulating endothelial progenitor cells inversely correlate with risk factors for coronary artery disease. Circ Res. 2001;89(1):E1-E7.

30. Strawn WB, Chappell MC, Dean RH, Kivlighn S, Ferrario CM. Inhibition of early atherogenesis by losartan in monkeys with diet-induced hypercholesterolemia. Circulation. 2000;101(13): 1586-1593.

31. Wassmann S, Czech T, van Eickels M, Fleming I, Bohm M, Nickenig G. Inhibition of diet-induced atherosclerosis and endothelial dysfunction in apolipoprotein E/angiotensin II type 1A receptor double-knockout mice. Circulation. 2004;110(19):3062-3067.
32. Richmond RS, Tallant EA, Gallagher PE, Ferrario CM, Strawn WB. Angiotensin II stimulates arachidonic acid release from bone marrow stromal cells. J Renin Angiotensin Aldosterone Syst. 2004;5(4):176-182.

33. Strawn WB, Richmond RS, Ann Tallant E, Gallagher PE, Ferrario CM. Renin-angiotensin system expression in rat bone marrow haematopoietic and stromal cells. Br J Haematol. 2004;126(1):120-126.

34. Strawn WB, Ferrario CM. Angiotensin II AT1 receptor blockade normalizes $\mathrm{CD} 11 \mathrm{~b}+$ monocyte production in bone marrow of hypercholesterolemic monkeys. Atherosclerosis. 2008;196(2):624-632.

35. Santos RA, Simoes e Silva AC, Maric C, et al. Angiotensin-(1-7) is an endogenous ligand for the $\mathrm{G}$ protein-coupled receptor Mas. Proc Natl Acad Sci US A. 2003;100(14):8258-8263.

36. Santos RA, Castro CH, Gava E, et al. Impairment of in vitro and in vivo heart function in angiotensin-(1-7) receptor MAS knockout mice. Hypertension. 2006;47(5):996-1002.

37. Castro CH, Santos RA, Ferreira AJ, Bader M, Alenina N, Almeida AP. Evidence for a functional interaction of the angiotensin-(1-7) receptor Mas with AT1 and AT2 receptors in the mouse heart. Hypertension. 2005;46(4):937-942.

38. Dias-Peixoto MF, Santos RA, Gomes ER, et al. Molecular mechanisms involved in the angiotensin-(1-7)/Mas signaling pathway in cardiomyocytes. Hypertension. 2008;52(3):542-548.

39. Gallagher PE, Ferrario CM, Tallant EA. MAP Kinase/phosphatase pathway mediates the regulation of ACE2 by angiotensin peptides. Am J Physiol Cell Physiol. 2008;295(5):C1169-C1174.

40. Sampaio WO, Henrique de Castro C, Santos RA, Schiffrin EL, Touyz RM. Angiotensin-(1-7) counterregulates angiotensin II signaling in human endothelial cells. Hypertension. 2007;50(6):1093-1098.

41. Crackower MA, Sarao R, Oudit GY, et al. Angiotensin-converting enzyme 2 is an essential regulator of heart function. Nature. 2002;417(6891):822-828.

42. Ferrario CM. Angiotensin-converting enzyme 2 and angiotensin(1-7): an evolving story in cardiovascular regulation. Hypertension. 2006;47(3):515-521.

43. Lu H, Rateri DL, Feldman DL, et al. Renin inhibition reduces hypercholesterolemia-induced atherosclerosis in mice. J Clin Invest. 2008;118(3):984-993.

44. Brenner BM, Cooper ME, de Zeeuw D, et al. Effects of losartan on renal and cardiovascular outcomes in patients with type 2 diabetes and nephropathy. N Engl J Med. 2001;345(12):861-869.

45. Cohn JN, Tognoni G. A randomized trial of the angiotensinreceptor blocker valsartan in chronic heart failure. $N$ Engl J Med. 2001;345(23):1667-1675.

46. Dickstein K, Kjekshus J. Effects of losartan and captopril on mortality and morbidity in high-risk patients after acute myocardial infarction: the OPTIMAAL randomised trial. Optimal Trial in Myocardial Infarction with Angiotensin II Antagonist Losartan. Lancet. 2002;360(9335): 752-760.

47. Lewis EJ, Hunsicker LG, Clarke WR, et al. Renoprotective effect of the angiotensin-receptor antagonist irbesartan in patients with nephropathy due to type 2 diabetes. N Engl J Med. 2001;345(12):851-860.

48. Parving HH, Lehnert H, Brochner-Mortensen J, Gomis R, Andersen S, Arner P. The effect of irbesartan on the development of diabetic nephropathy in patients with type 2 diabetes. $N$ Engl J Med. 2001;345(12):870-878.

49. Pfeffer MA, McMurray JJ, Velazquez EJ, et al. Valsartan, captopril, or both in myocardial infarction complicated by heart failure, left ventricular dysfunction, or both. N Engl J Med. 2003;349(20):1893-1906.

50. Pfeffer MA, Swedberg K, Granger CB, et al. Effects of candesartan on mortality and morbidity in patients with chronic heart failure: the CHARM-Overall programme. Lancet. 2003;362(9386):759-766.

51. The_ONTARGET_Investigators. Telmisartan, ramipril, or both in patients at high risk for vascular events. $N$ Engl J Med. 2008;358: 1547-1559.

52. Strawn WB, Ferrario CM, Tallant EA. Angiotensin-(1-7) reduces smooth muscle growth after vascular injury. Hypertension. 1999; 33(1 Pt 2):207-211. 
53. Ishiyama Y, Gallagher PE, Averill DB, Tallant EA, Brosnihan KB, Ferrario CM. Upregulation of angiotensin-converting enzyme 2 after myocardial infarction by blockade of angiotensin II receptors. Hypertension. 2004;43(5):970-976.

54. Ferrario CM, Trask AJ, Jessup JA. Advances in biochemical and functional roles of angiotensin-converting enzyme 2 and angiotensin-(1-7) in regulation of cardiovascular function. Am J Physiol Heart Circ Physiol. 2005;289(6):H2281-H2290.

55. Igase M, Strawn WB, Gallagher PE, Geary RL, Ferrario CM. Angiotensin II AT1 receptors regulate ACE2 and angiotensin-(1-7) expression in the aorta of spontaneously hypertensive rats. $\mathrm{Am} J$ Physiol Heart Circ Physiol. 2005;289(3):H1013-H1019.

56. Tallant EA, Ferrario CM, Gallagher PE. Angiotensin-(1-7) inhibits growth of cardiac myocytes through activation of the mas receptor. Am J Physiol Heart Circ Physiol. 2005;289(4):H1560-H1566.

57. Yokoyama H, Averill DB, Brosnihan KB, Smith RD, Schiffrin EL, Ferrario CM. Role of blood pressure reduction in prevention of cardiac and vascular hypertrophy. Am J Hypertens. 2005;18(7):922-929.

58. Agata J, Ura N, Yoshida H, et al. Olmesartan is an angiotensin II receptor blocker with an inhibitory effect on angiotensin-converting enzyme. Hypertens Res. 2006;29(11):865-874.

59. Trask AJ, Averill DB, Ganten D, Chappell MC, Ferrario CM. Primary role of angiotensin-converting enzyme-2 in cardiac production of angiotensin-(1-7) in transgenic Ren-2 hypertensive rats. Am J Physiol Heart Circ Physiol. 2007;292(6):H3019-H3024.

60. Trask AJ, Ferrario CM. Angiotensin-(1-7): pharmacology and new perspectives in cardiovascular treatments. Cardiovasc Drug Rev. 2007;25(2):162-174.

61. Gallagher PE, Ferrario CM, Tallant EA. Regulation of ACE2 in cardiac myocytes and fibroblasts. Am J Physiol Heart Circ Physiol. 2008;295(6):H2373-H2379.

62. Igase M, Kohara K, Nagai T, Miki T, Ferrario CM. Increased expression of angiotensin converting enzyme 2 in conjunction with reduction of neointima by angiotensin II type 1 receptor blockade. Hypertens Res. 2008;31(3):553-559.

63. Fliser D, Buchholz K, Haller H. Antiinflammatory effects of angiotensin II subtype 1 receptor blockade in hypertensive patients with microinflammation. Circulation. 2004;110(9):1103-1107.

64. Bahlmann FH, de Groot K, Mueller O, Hertel B, Haller H, Fliser D. Stimulation of endothelial progenitor cells: a new putative therapeutic effect of angiotensin II receptor antagonists. Hypertension. 2005;45(4):526-529.

65. Stumpe K, Agabiti-Rosei E, Zielinski T, et al. Carotid intima-media thickness and plaque volume changes following 2-year angiotensin IIreceptor blockade. The multicentre olmesartan atherosclerosis regresssion evaluation (MORE) study. Ther Adv Cardiovasc Dis. 2007; 1(2):97-106.

66. Naya M, Tsukamoto T, Morita K, et al. Olmesartan, but not amlodipine, improves endothelium-dependent coronary dilation in hypertensive patients. J Am Coll Cardiol. 2007;50(12):1144-1149.

67. Smith R, Yokoyama H, Averill DB, Schiffrin EL, Ferrario CM. Reversal of vascular hypertrophy in hypertensive patients through blockade of angiotensin II receptors. JASH. 2008;2(3):165-172.

68. Smith RD, Yokoyama H, Averill DB, et al. The protective effects of angiotensin II blockade with olmesartan medoxomil on resistance vessel remodeling (The VIOS study): rationale and baseline characteristics. Am J Cardiovasc Drugs. 2006;6(5):335-342.

69. Yamamoto E, Dong YF, Kataoka K, et al. Olmesartan prevents cardiovascular injury and hepatic steatosis in obesity and diabetes, accompanied by apoptosis signal regulating kinase-1 inhibition. Hypertension. 2008;52(3):573-580.

70. Izumiya Y, Kim S, Izumi Y, et al. Apoptosis signal-regulating kinase 1 plays a pivotal role in angiotensin II-induced cardiac hypertrophy and remodeling. Circ Res. 2003;93(9):874-883.

71. Porteri E, Rodella L, Rizzoni D, et al. Effects of olmesartan and enalapril at low or high doses on cardiac, renal and vascular interstitial matrix in spontaneously hypertensive rats. Blood Press. 2005;14(3):184-192.
72. Yoshida J, Yamamoto K, Mano T, et al. AT1 receptor blocker added to ACE inhibitor provides benefits at advanced stage of hypertensive diastolic heart failure. Hypertension. 2004;43(3):686-691.

73. Miyazaki M, Takai S. Anti-atherosclerotic efficacy of olmesartan. J Hum Hypertens. 2002;16 Suppl 2:S7-S12.

74. Takai S, Jin D, Sakaguchi M, Muramatsu M, Miyazaki M. The regressive effect of an angiotensin II receptor blocker on formed fatty streaks in monkeys fed a high-cholesterol diet. J Hypertens. 2005;23(10):1879-1886.

75. Kato M, Sada T, Mizuno M, Kitayama K, Inaba T, Koike H. Effect of combined treatment with an angiotensin II receptor antagonist and an HMG-CoA reductase inhibitor on atherosclerosis in genetically hyperlipidemic rabbits. J Cardiovasc Pharmacol. 2005;46(4):556-562.

76. van der Hoorn JW, Kleemann R, Havekes LM, Kooistra T, Princen HM, Jukema JW. Olmesartan and pravastatin additively reduce development of atherosclerosis in APOE*3Leiden transgenic mice. J Hypertens. 2007;25(12):2454-2462.

77. Yamamoto E, Yamashita T, Tanaka T, et al. Pravastatin enhances beneficial effects of olmesartan on vascular injury of salt-sensitive hypertensive rats, via pleiotropic effects. Arterioscler Thromb Vasc Biol. 2007;27(3):556-563.

78. Tsuda M, Iwai M, Li JM, et al. Inhibitory effects of AT1 receptor blocker, olmesartan, and estrogen on atherosclerosis via anti-oxidative stress. Hypertension. 2005;45(4):545-551.

79. Kato M, Sada T, Chuma H, et al. Severity of hyperlipidemia does not affect antiatherosclerotic effect of an angiotensin II receptor antagonist in apolipoprotein E-deficient mice. J Cardiovasc Pharmacol. 2006;47(6):764-769.

80. Koga K, Yamagishi S, Takeuchi M, et al. CS-886, a new angiotensin II type 1 receptor antagonist, ameliorates glomerular anionic site loss and prevents progression of diabetic nephropathy in Otsuka Long-Evans Tokushima fatty rats. Mol Med. 2002;8(10):591-599.

81. Kobori H, Ozawa Y, Suzaki Y, Nishiyama A. Enhanced intrarenal angiotensinogen contributes to early renal injury in spontaneously hypertensive rats. J Am Soc Nephrol. 2005;16(7):2073-2080.

82. Nangaku M, Miyata T, Sada T, et al. Anti-hypertensive agents inhibit in vivo the formation of advanced glycation end products and improve renal damage in a type 2 diabetic nephropathy rat model. $J$ Am Soc Nephrol. 2003;14(5):1212-1222.

83. Izuhara $\mathrm{Y}$, Nangaku $\mathrm{M}$, Inagi $\mathrm{R}$, et al. Renoprotective properties of angiotensin receptor blockers beyond blood pressure lowering. $J \mathrm{Am}$ Soc Nephrol. 2005;16(12):3631-3641.

84. Nakamura $\mathrm{H}$, Inoue $\mathrm{T}$, Arakawa $\mathrm{N}$, et al. Pharmacological and pharmacokinetic study of olmesartan medoxomil in animal diabetic retinopathy models. Eur J Pharmacol. 2005;512(2-3):239-246.

85. Jinno T, Iwai M, Li Z, et al. Calcium channel blocker azelnidipine enhances vascular protective effects of AT1 receptor blocker olmesartan. Hypertension. 2004;43(2):263-269.

86. Liu HW, Iwai M, Takeda-Matsubara Y, et al. Effect of estrogen and AT1 receptor blocker on neointima formation. Hypertension. 2002;40(4):451-457.

87. Min LJ, Mogi M, Li JM, Iwanami J, Iwai M, Horiuchi M. Aldosterone and angiotensin II synergistically induce mitogenic response in vascular smooth muscle cells. Circ Res. 2005;97(5):434-442.

88. Mukai Y, Shimokawa H, Higashi M, et al. Inhibition of reninangiotensin system ameliorates endothelial dysfunction associated with aging in rats. Arterioscler Thromb Vasc Biol. 2002;22(9):1445-1450.

89. Ferrario CM. The role of angiotensin antagonism in stroke prevention in patients with hypertension: focus on losartan. Curr Med Res Opin. 2004;20(11):1797-1804.

90. Fabia MJ, Abdilla N, Oltra R, Fernandez C, Redon J. Antihypertensive activity of angiotensin II AT1 receptor antagonists: a systematic review of studies with $24 \mathrm{~h}$ ambulatory blood pressure monitoring. J Hypertens. 2007;25(7):1327-1336.

91. Koike H, Sada T, Mizuno M. In vitro and in vivo pharmacology of olmesartan medoxomil, an angiotensin II type AT1 receptor antagonist. J Hypertens Suppl. 2001;19(1):S3-S14. 
92. Yanagisawa H, Amemiya Y, Kanazaki T, et al. Nonpeptide angiotensin II receptor antagonists: synthesis, biological activities, and structure-activity relationships of imidazole-5-carboxylic acids bearing alkyl, alkenyl, and hydroxyalkyl substituents at the 4-position and their related compounds. J Med Chem. 1996;39(1):323-338.

93. Le MT, Pugsley MK, Vauquelin G, Van Liefde I. Molecular characterisation of the interactions between olmesartan and telmisartan and the human angiotensin II AT1 receptor. Br J Pharmacol. 2007;151(7):952-962.

94. Ichikawa S, Takayama Y. Long-term effects of olmesartan, an Ang II receptor antagonist, on blood pressure and the renin-angiotensinaldosterone system in hypertensive patients. Hypertens Res. 2001; 24(6):641-646.

95. Schindler C, Brosnihan KB, Ferrario CM, et al. Comparison of inhibitory effects of irbesartan and atorvastatin treatment on the renin angiotensin system (RAS) in veins: a randomized double-blind crossover trial in healthy subjects. J Clin Pharmacol. 2007;47(1):112-120.

96. Iyer SN, Averill DB, Chappell MC, Yamada K, Allred AJ, Ferrario CM. Contribution of angiotensin-(1-7) to blood pressure regulation in saltdepleted hypertensive rats. Hypertension. 2000;36(3):417-422.

97. Moriguchi A, Tallant EA, Matsumura K, et al. Opposing actions of angiotensin-(1-7) and angiotensin II in the brain of transgenic hypertensive rats. Hypertension. 1995;25(6):1260-1265.

98. Campagnole-Santos MJ, Heringer SB, Batista EN, Khosla MC, Santos RA. Differential baroreceptor reflex modulation by centrally infused angiotensin peptides. Am J Physiol. 1992;263(1 Pt 2):R89-R94.

99. Grobe JL, Mecca AP, Lingis M, et al. Prevention of angiotensin II-induced cardiac remodeling by angiotensin-(1-7). Am J Physiol Heart Circ Physiol. 2007;292(2):H736-H742.
100. Ferreira AJ, Santos RA, Almeida AP. Angiotensin-(1-7): cardioprotective effect in myocardial ischemia/reperfusion. Hypertension. 2001;38(3 Pt 2): 665-668.

101. Ferreira AJ, Santos RA, Almeida AP. Angiotensin-(1-7) improves the post-ischemic function in isolated perfused rat hearts. Braz J Med Biol Res. 2002;35(9):1083-1090.

102. DelliPizzi AM, Hilchey SD, Bell-Quilley CP. Natriuretic action of angiotensin(1-7). Br J Pharmacol. 1994;111(1):1-3.

103. Heller J, Kramer HJ, Maly J, Cervenka L, Horacek V. Effect of intrarenal infusion of angiotensin-(1-7) in the dog. Kidney Blood Press Res. 2000;23(2):89-94.

104. Vallon V, Heyne N, Richter K, Khosla MC, Fechter K. [7-D-ALA]angiotensin 1-7 blocks renal actions of angiotensin 1-7 in the anesthetized rat. J Cardiovasc Pharmacol. 1998;32(1):164-167.

105. Loot AE, Roks AJ, Henning RH, et al. Angiotensin-(1-7) attenuates the development of heart failure after myocardial infarction in rats. Circulation. 2002;105(13):1548-1550.

106. Ferrario CM, Martell N, Yunis C, et al. Characterization of angiotensin(1-7) in the urine of normal and essential hypertensive subjects. Am J Hypertens. 1998;11(2):137-146.

107. Luque M, Martin P, Martell N, Fernandez C, Brosnihan KB, Ferrario CM. Effects of captopril related to increased levels of prostacyclin and angiotensin-(1-7) in essential hypertension. J Hypertens. 1996;14(6):799-805.

108. Ferrario CM, Smith RD, Brosnihan B, et al. Effects of omapatrilat on the renin-angiotensin system in salt-sensitive hypertension. Am J Hypertens. 2002;15(6):557-564.

109. Schmeider RE, Hilgers KF, Schlaich MP. Renin-angiotensin system and cardiovascular risk. Lancet. 2007;369:1208-1219. 